\title{
Developing Reading Materials for Advanced ESL Learners
}

\author{
Linda Seright and Joan Thompson
}

\begin{abstract}
Many intermediate and advanced ESL learners, adults particularly, have specific needs in reading, needs which existing instructional materials do not properly address. This paper discusses a curriculum development project undertaken by teachers dissatisfied with the program used for teaching reading in an advancedlevel ESL course.

Certain inadequacies were recognized in the program. Selections were not representative of material students would be likely to read, and exercises dealt only marginally with reading skills.

The steps taken by teachers resulted in a major re-orientation to reading instruction. Based on findings yielded by a sur-
\end{abstract}

vey of learners and a study of recent literature, instructional objectives were established in two areas: a) skills to be developed and b) text-types to be presented. Following that, texts were selected, and skill-oriented exercises were developed. After classroom trials, the materials were implemented in the advanced course as a new reading program, and a system for ongoing revision was organized.

In describing developmental procedures and sample materials, this paper provides working guidelines for handling problems relating to the teaching of reading.

In recent years, it seems, much of the attention in second language teaching has been directed towards the development of oral proficiency. Yet, many students, particularly adults at intermediate or advanced levels, need to improve their reading ability as much as or perhaps more than oral skills. Teachers who work with these students often find that existing curricula and instructional materials do not properly address the students' needs in reading.

A problem of this nature was confronted by teachers working within the Advanced English Course at the Canadian Forces Language School in St. Jean. In this paper, the problem and the proposed solution will be discussed, and samples of various instructional materials developed will be presented. We hope to provide a procedural framework which may be of assistance to other teachers in solving similar problems related to ESL reading instruction.

\section{BACKGROUND TO THE MATERIALS DEVELOPMENT PROJECT}

The St. Jean language school offers an intensive 15-week advanced English course involving 25 hours a week of classroom study, the pri- 
mary objective of which is to develop high-level proficiency in reading and writing. The students are career military personnel, francophones, who already possess excellent aural-oral ability. For them, the acquisition of greater competence in reading is either desirable or necessary for their professional development.

For some time, both teachers and administrators associated with the advanced course had been dissatisfied with the program used for reading instruction. Inadequacies were recognized with respect to a) the texts themselves, b) the exercises based on those texts, and c) the overall organization of the program. Firstly, the texts were not sufficiently varied in nature; nor were they representative of material students would be likely to read at work or at home. Moreover, many texts were not authentic and some were dated. Secondly, the accompanying exercises (e.g., word definition, general comprehension questions, exercises revolving around grammar points and/or writing skills) dealt only partially with reading skills. There was also a lack of variety; the same exercises followed each text in the same order. Finally, the program did not reflect any underlying organization based on clearly defined objectives for reading skill development, and there was no gradation according to text sophistication or degree of task (exercise) difficulty.

In an attempt to solve the problem outlined above, it was decided to develop a new reading program. The new program would a) be based on clearly defined objectives for reading, b) incorporate textual material that students would probably be interested in reading and c) be organized so as to reflect a progression of increasing complexity in texts and related tasks. Prior to program development, research was undertaken in two areas: a) student needs and interests in reading and b) specific skills involved in reading and techniques for developing these skills.

A number of recently published texts and articles pertaining to the teaching of reading were consulted. This review served two functions: a) it helped to clarify the specific skills involved in reading comprehension and $b$ ) it provided many useful suggestions as to task-types which could be included in a reading program. Several texts found to be very helpful are given in the reference list at the end of this paper.

A questionnaire was prepared and given to students enrolled in the advanced course at the time when the research was conducted (October to December, 1984). In the questionnaire, students were asked to indicate the type of written material they a) had to read at work, b) would like to read, and c) would like to see included in a reading course. They were also asked to pick out from a list of reading activities (e.g., finding the main idea, using context to guess word meaning, working on improving reading speed) those that they preferred. A total of 57 questionnaires were completed and subsequently analyzed. 
Of the material students were required to read at work (i.e., routine orders, directives, memos, trades-related instruction manuals, reports, and some specialized military documents), only one type-reportsappeared to be feasible or suitable for use in an advanced reading course. The other text-types were either too simplistic in nature, too highly specialized for a general course, or simply unobtainable due to military restrictions.

On the other hand, the responses pertaining to what students would like to read and what they wanted to see included in a reading coursewhich were essentially the same-reflected a wide variety of interests and played a large role in determining the text-types selected for the reading program. High on the list of preferred reading material were newspapers and magazines, closely followed by humour and history. There was also a significant interest in reading science texts, short stories, biographies, novels, science fiction, travel literature, detective stories, and instructional manuals.

\section{OBJECTIVES}

Two main instructional objectives were established. These pertain to a) text-types and b) reading skills or strategies. The first reflected text preferences expressed in the questionnaire, and the second was based on findings from the review of the literature coupled with preferred reading activities identified in questionnaires.

Objective A

To enable students to deal effectively with (i.e., read, comprehend and evaluate) a wide range of text-types (fiction, non-fiction, humorous, factual, biographical, documentary, etc.):

1. newspaper articles

2. magazine articles

3. reports (military reports, consumer reports, reports of studies)

4. graphs

5. technical texts

6. essays (argument, comparison and contrast)

7. historical accounts

8. anecdotes

9. short biographies

10. short stories

11. detective stories

\section{Objective $B$}

To enable students to develop skills or strategies which facilitate reading comprehension:

1. guessing the meaning of unfamiliar words through the use of 
a) context clues

b) analysis of component parts (stems and affixes)

2. locating core elements in long, complex sentences

3. understanding cohesive devices:
a) pronoun reference
b) logical connectors

4. identifying the main idea and supporting details

5. determining the sequence of steps or events

6. predicting text content

7. skimming

8. scanning for specific facts

9. finding the organizational plan

10. making inferences

11. distinguishing between fact and opinion or supposition

12. spotting writer bias

13. evaluating content and organization

It should be noted that 10 through 13 above are considered to be higher-level reading skills as the information is rarely explicitly stated in the text and the reader is called upon to make judgements. By way of contrast, the others may be termed lower-level skills (or strategies).

\section{GENERAL PLAN OF PROGRAM}

The next step in the development of the new reading program involved the mapping out of an overall plan or design showing units of instruction based on a specific text-type with a specific skill/strategy focus. The number of component units was set at 30 . The global plan was designed to reflect a progression from lower-level to higher-level reading skills (or strategies). Earlier units would focus on guessing word meaning, strategies for coping with complex sentence structure, predicting, skimming, and scanning while in later units, the emphasis would be given to inferencing and skills which play a role in critical reading. Provision was also made for a recycling of skill/strategies. Once a skill/ strategy was introduced, it would be taken up again in subsequent units.

Another feature of the overall design is that along with the complexity of accompanying tasks, the length and the estimated difficulty of texts increase throughout the program. The texts used in the first three units are very short, consisting of either a single sentence or paragraph. Units 4 through 12 revolve around newspaper articles, graphs, brief military reports, consumer reports and advertisements. Following that, short magazine articles, factual and simply written, are presented. In the second half of the program, where the majority of tasks involve analysis and evaluation of text content, organization, and style, the texts used (e.g., humorous pieces, essays, newsmagazine stories, technical 
texts, short stories) tend to be several pages in length, to reflect a certain point of view, and to treat controversial issues.

Once the general plan had been laid out, individual units were developed. The development involved choosing a specific text or texts for each unit, specifying instructional objectives, and devising tasks.

After individual units were developed, they were tried out in the classroom. Following trials, a few revisions were made. The program as a whole was then implemented within the Advanced English Course.

First, an abbreviated version of one unit (i.e., Unit 10) will be shown in order to illustrate a complete unit. Then, a number of the tasks used in the program will be presented.

\section{Complete Unit Sample}

\section{UNIT 10}

TEXT-TYPE: consumer report

AIM: to train students to make quick and judicious use of consumer reports

\section{OBJECTIVES:}

1. to encourage students to predict content, identify expectations

2. to provide practice in scanning to locate specific facts quickly

3. to enable students to evaluate reports with respect to certain criteria (e.g., manner of presentation, ease of reference, usefulness of information given)

TEXT: a report on a specific product (e.g., pens, cars, toasters) taken from a consumer magazine

TASKS:

1. Pre-reading (Tasks or questions relate to objective 1)

a) What is a consumer report?

b) Why or when would you read a consumer report?

c) What does a consumer report contain? i) ii) iii)

d) List below the questions you would expect a report on brands of product $\mathrm{X}$ to answer.
i)
ii)
iii)

e) What points of comparison (criteria) do you think will be used in the report? (Students are asked to complete a chart indicating criteria and brands.)

2. Reading (Tasks relate to objective 2)

a) Scan the report to find answers to your questions in d) above.

b) Scan the report to find the points of comparison used.

c) What were the technical tests supposed to determine?

3. Evaluation (Tasks relate to objective 3)
a) Did the report provide the facts you wanted to know?
b) How easy was it to find the facts you looked for? 
c) Rate the presentational format: amount of text versus tables, ease of reference, etc.

d) Is the report completely objective or is there a bias? Justify your answer.

\section{SIMPLE TASKS}

\section{Context Clues}

The following exercises are designed to lessen students' reliance upon the dictionary by encouraging them to use contextual clues to guess the meaning of unfamiliar words-a procedure which should increase reading speed.

1. Provide a meaning for the underlined nonsense word in each of the following sentences. Use the clues provided by the context.

e.g. When I returned my Christmas present to the store, the cashier gave me a zurple.

2. Using the context, give a general definition (synonym, explanation or description) of the underlined words in each sentence. (Sentences are taken from current magazines, newspapers, etc.)

e.g. "It was not until the Great Recession of the 1980's that most Canadians confronted the discomfiting realization that customary safety nets were not working any more." (Maclean's, Jan. 1, 1985)

\section{Sentence Simplification}

Some popular publications (e.g., newsmagazines) tend to use an abundance of long and very structurally complex sentences which students often find difficult to process. The exercise shown below is intended to provide students with a useful strategy for coping with these sentences:

One way of dealing with a long, complex sentence is to identify its core (i.e., main subject, verb, object, etc.). Try to pick out the core elements in these sentences.

e.g. "Instead of cringing before uncertain economic indicators, shaking fists at politicians or bowing to social restraints, most Canadians at mid-decade are confident about themselves and optimistic about their country." (Maclean's, Jan. 7, 1985)

\section{Predictions}

The ability to predict what will be discussed in a text or what is 
coming next in a sentence or paragraph plays an important role in reading comprehension. The following series of tasks aims at developing this ability.

1. The following is a poor photocopy of a text. The ends of lines have been cut off. You are asked to complete the word at the end of each line. (Text follows.)

2. Use the context in the following sentences to predict the missing words.

e.g. After checking the waist size, he removed the from the rack and tried them on.

3. Read the opening sentences of paragraphs given below and, after each of them, list the things you think might be mentioned in the paragraph.

e.g. "Dynamo Dolly Parton is a woman of many parts." (Maclean's, Jan. 7, 1985)

\section{Newspapers}

Scanning for specific facts and discovering the organizational structure of newspaper articles are the focus of the two exercises below.

1. Scan (i.e., look over quickly without reading everything) the story below to find the following information:

fact a) fact b) fact c)

2. a) Quickly skim the following story, underlining the sentences or words in each paragraph that contain the essential or main idea.

b) Is there a paragraph in which you underlined more words than in any. other? If yes, which paragraph is it?

c) Which paragraph contains the news, that is, the most recent or new information?

It might be noted that the object of exercise 2 above is to bring to students' attention the typical structure of a newspaper article; i.e., the most important facts or the latest events in a continuing news story appear in the lead paragraph while subsequent paragraphs add information of lesser importance.

\section{Graphs}

Since reports often contain graphs, students like ours who read reports need to be able to interpret this kind of information. Sample tasks using graphs appear below. The accompanying graphs (not shown), from which students are to select two, were taken from military reports.

1. Using one of the graphs selected, write an interpretation of 
the graph in which you identify the variables and the central idea conveyed by the graph.

2. With the other, prepare an explanation of the graph to be presented orally using notes.

\section{Reports (military)}

The following exercises are used in conjunction with a short report which appeared in Defence 83, a lengthy annual report on the Canadian Armed Forces. They relate to 1) organization and 2) assessment of text content.

1. Read the first sentence in each paragraph. Based on first sentences, indicate what you think the topic of each paragraph is.

paragraph 1

paragraph 2

2. Based on what is stated in the text, decide whether the following statements are True or False or whether there is insufficient information for making a judgement.

e.g. Women can choose any trade or classification.

Women serve at all ranks.

\section{Advertisements}

These tasks focus on a) distinguishing between objective and biased writing, b) identifying techniques used in deception or suggestion, and c) inferring what is not explicit.

1. Read the advertisement. Pick out any objective statements.

2. Read the ad (car ad). As you read, try to determine what impression the writer wants you to have of the car.

3. Which of the statements listed below best describe the main impression of the car that the ad tries to create?

4. Describe the techniques used to create this impression and give examples.

5. What information is omitted? Why?

6. Write a short profile of a typical owner of car X.

Refer to age, sex, job, career aspirations, etc.

\section{Magazine Articles}

The tasks below involve predicting, locating the main idea and main points quickly, spotting key words, and finding the organizational plan.

1. Read the title and subheading(s). Briefly state what you expect the theme to be.

2. To determine the main idea quickly, read the first and last paragraphs. State the main idea in 30 words or less.

3. Reading the introductory sentences of the other paragraphs 
usually enables you to locate quickly the supporting points used to develop the main idea. Do this and then list the specific points used.

4. Ideas are often tied together through the repetition of key words and phrases. This repetition enables the author to achieve unity within the article and to reinforce his point. Skim the text, picking out key words and phrases repeated.

5. A strategy for rapid reading with comprehension is to find the underlying organizational plan. This involves determining the function each paragraph or group of paragraphs performs. Complete the following plan for the article. (A prepared outline is provided.)

\section{Biographical Articles}

Biographical articles are often written from a particular perspective. The following questions accompany an article on a Canadian athlete and are designed to focus students' attention on the author's perspective and its influence upon content selection and vocabulary choice.

1. Judging from the title and subtitle, from what perspective do you think this biography has been written?

2. What details of the athlete's past does the author focus on to reflect his opinion (i.e., point of view)?

3. The author communicates his view of the athlete through his language as well as through the biographical details he chooses to mention. Go through the text noting the adjectives used to describe the athlete and her activities. What image emerges from these words?

\section{Humorous Selections}

The reading program includes two humorous texts; one is a sports anecdote and the other is a highly imaginative, also very distorted, account of historial events. The exercises illustrated below were devised for the latter. These exercises centre around comprehending humour and recognizing how it is derived.

1. Indicate which points (listed previously) are distortions. Show how they distort the facts and explain why the distortion is humorous.

2. In addition to distortion, the writer uses absurdity (i.e., invents absurd anecdotes) to produce humorous effects. Skim the text to find examples.

3. A third source of humour lies in the writer's style. He mixes several varieties of language in one text: formal language such as that found in academic (historical) texts is blended with informal phrases, colloquialisms, and at times, blunt or crude expressions. For example ... (An example from the text is 
provided.) Now skim the first two pages of the text, underlining examples of informal phrases that clash with the formal style used frequently throughout the text.

\section{Two Sources of Information}

In one unit, students work with two sources of information, a written text and a short film, both of which describe and explain the same phenomenon-"stress". The underlying objective in the unit is to equip students with strategies for using multiple sources when researching a topic. Some of the tasks assigned to students are shown below.

1. Pre-reading

a) How do you define stress?

b) Have you ever taken a stress management course?

2. On viewing the film

As you view the film, fill in the information requested in the outline you have been given. (The outline is organized so as to enable students to record the main points.)

3. Comparison of film and text

a) Skim the text in order to locate these points: i) the definition of stress, ii) the causes, etc.

b) How do the text and the film differ on the above points?

4. Evaluation

a) Is one source of information superior to the other with respect to i) clarity, ii) accuracy, iii) appropriateness to you the user?

b) Who is the film intended for? Who is the text aimed at?

\section{CONCLUDING REMARKS}

As stated previously, the reading program developed has been implemented within the Advanced English Course given in St. Jean; it now constitutes an important part of the curriculum. This, however, by no means signals an end of the developmental process. On the contrary, a system for ongoing revision based on continued feedback from students and teachers has been organized. It is expected that the reading program will undergo constant revision as texts become dated and are replaced by more recent ones, as new tasks are invented, and more importantly, as student needs and/or interests change.

\section{REFERENCES}

Baudoin, E.M.G., Bober, E., Clark, M.A., Dobson, B., Silberstein, S.V. (1977). Reader's choice: A reading skills textbook for students of English as a second language. Ann Arbor: University of Michigan Press. 
Dubin, F., and Olshtain, E. (1981). Reading by all means. Reading, Mass.: Addison-Wesley.

Golder, D. (1980). The newspaper and you: A reading and writing skills workbook. New York: Amsco School Publications.

Grellet, F. (1981). Developing reading skills: A practical guide to reading comprehension exercises. Cambridge: Cambridge University Press.

Harmer, J. (1983). The practice of English language teaching. London: Longman.

\section{THE AUTHORS}

Linda Seright has worked at the Canadian Forces Language School since 1969. Her duties have included classroom teaching, teacher training and supervision, curriculum development, and testing. She has an M. Ed. (McGill) in teaching French and an M.A. (Concordia) in Applied Linguistics. She was a presenter at both SPEAQ and the TESL Ontario conferences in 1985.

Joan Thompson spent eleven years at the Canadian Forces Language School where her duties involved classroom teaching, teacher training and supervision, curriculum development, and testing. She is presently teaching ESL at the Collège Militaire Royal in St. Jean. She has a TESL Certificate and an M.A. in English Literature. In 1985, she was a presenter at both the SPEAQ and the TESL conferences. Previous presentations at SPEAQ have focussed on the use of video in the classroom. 